\title{
Por uma variável morfossintática: delimitações teóricas e aplicadas à expressão de passado no espanhol
}

\author{
For a morphosyntactic variable: theoretical and applied delimitations \\ to the expression of past tense in Spanish
}

Leandro Silveira de Araujo ${ }^{1}$

Doutor em Linguística e Língua Portuguesa pela Universidade Estadual Paulista "Júlio de Mesquita Instituto de Letras e Linguística da Universidade Federal de Uberlândia (ILEEL/UFU), com projeto de pesquisa em variaçao e mudança no espanhol e em contraste com o português. É autor do livro:

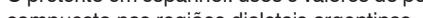
E-mail:
RESUMO: Este trabalho visa avaliar como a definição de variável linguística pode se ajustar ao estudo da variação entre as formas do pretérito perfecto em variedades diatópicas da língua espanhola. Para tanto, partimos do percurso epistemológico que envolve a definição do conceito dentro do quadro teórico da Teoria da Variação e Mudança linguística. Em seguida, tratamos especificamente do estudo das formas do pretérito perfecto mostrando como a norma-padrão define o contexto de uso categórico da forma simpes (cante) e composta (he cantado) e como os estudos descritivos apresentam possibilidades variáveis de uso das mesmas formas. Frente ao cenário de variação, propomos aplicar o conceito de variável linguística apenas àqueles contextos de uso em que ambas as formas expressam efetivamente o mesmo valor, isso é, em que tenham as particularidades neutralizadas no discurso.

PaLAVRAS-CHAVE: Variável linguística; Pretérito Perfecto; Língua Espanhola; Variação Linguística.

ABSTRACT: This paper evaluates how the definition of linguistic variable can be adjusted to the study of variation among the forms of the 'pretérito perfecto' in distopic varieties of Spanish. Therefore, we start from the epistemological course that involves the definition of variable within the theoretical framework of the Theory of Language Variation and Change. Then, we specifically deal with the study of the forms of the 'pretérito perfecto', to show how the standard norm defines the context of categoric usage of simple (canté) and compound forms (he cantadado) and how the descriptive studies present variable possibilities of using the same forms. In the face of this scenario of variation, we propose to apply the concept of linguistic variable only to those contexts of usage in which both forms effectively express the same value, that is, in which they have their particularities neutralized in discourse.

KEYwords: Syntactic variable; Present Perfect; Spanish; Linguistic Variation. 


\section{Delimitações teóricas da variável sintática}

A pós a segunda metade do século $\mathrm{XX}$, a atenção à heterogeneidade linguística passa a ser a tônica dos estudos das línguas naturais. Uma vez formalizada a disciplina Sociolinguística, recupera-se efetivamente o pressuposto de que a língua(gem), como um organismo em estreita relação com o homem, deve ser estudada no interior da comunidade em que é falada, já que fatores sociais de ordem extralinguística, também gerenciam seu funcionamento. É esboçando a complexidade extralinguística que envolve o uso da língua que Chambers (2003) afirma:

The social class to which we belong imposes some norms of behavior on us and reinforces them by the strength of the example of the people with whom we associate most closely. The sub-elements of social class include education, occupation and type of housing, all of which play a role in determining the people with whom we will have daily contacts and more permanent relationships (CHAMBERS, 2003, p. 07) ${ }^{1}$.

Assim sendo, tal como nos mostra Labov (2008), o conhecimento do(s) comportamento(s) da língua deve partir da observação do modo como ela se insere na sociedade, posto que fatores extralinguísticos - como os apontados por Chambers (2003) - estão a todo momento determinando seu uso. Sintetizando esse pressuposto, Lavandera (1984) afirma que a grande contribuição da Sociolinguística foi comprovar que a linguagem é uma manifestação da conduta humana - a qual tenta organizar os indivíduos em grupos sociais. Em suas palavras,

\footnotetext{
<Tradução nossa> "A classe social a que pertencemos impõe-nos algumas normas de comportamento e as reforça graças à força do exemplo das pessoas com que nos associamos com maior proximidade. Os subelementos da classe social incluem educação, ocupação, tipo de residência e desempenham um papel em determinar as pessoas com quem teremos contatos diários e relacionamentos mais permanentes" (CHAMBERS, 2003, p. 07).
}

La meta de la descripción sociolinguísticava más allá de la descripción de la forma del código (gramática estructural) o del análisis de las intuiciones del hablante nativo y su capacidad para generar un número infinito de oraciones (gramática generativa). Apunta a desarrollar una teoría del lenguaje que define su objeto de estudio como el recurso más rico y más complejo para la comunicación humana, acumulado y manejado por la mente humana para utilizarlo con el propósito de lograr las formas de organización social y cultural que existen en las sociedades humanas (LAVANDERA, 1984, p. 156) ${ }^{2}$

A Sociolinguística mostra-nos que a língua é “um sistema ordenadamente heterogêneo em que a escolha entre alternativas linguísticas acarreta funções sociais e estilísticas", trata-se, portanto, de "um sistema que muda acompanhando as mudanças na estrutura social" (WEINREICH; LABOV; HERZOG, 2006, p. 99). Por isso é possível pensarmos em um modelo de heterogeneidade sistemática e ordenada, na qual uma variável linguística é controlada não só por padrões intrínsecos à língua, mas também por fatores de caráter extralinguístico. Em síntese, dentre as muitas contribuições aportadas pela Sociolinguística ao estudo da linguagem, destaca-se a percepção da diversidade linguística como uma característica inerente à linguagem. Por isso, a variação deve ser contemplada como uma condição do próprio sistema linguístico.

Sobre o processo de construção de novas formas variantes, Labov (2008) acusa a existência de uma grande quantidade de variações que a todo instante surge no uso da língua, mas que se extinguem tão rápido quanto aparecem. Não obstante, o autor explica-nos que algumas dessas variantes são mais recorrentes e, num segundo momento, podem "ser imitadas mais

2 <Tradução nossa> "A meta da descrição sociolinguística vai mais além da descrição da forma do código (gramatical estrutural) ou da análise das intuições do falante nativo e sua capacidade para gerar um número infinito de oraç̃es (gramatica gerativa) A oponta a desenvolvimento de uma teoria da gerar um número infinito de or açoes (gramatica gerativa). Aponta ao desenvolvimento de uma teoria da linguagem que define seu objeto de estudo cono or recurso mais rico e mais complexo para a conuno humana que existem nas sociedades humanas" (LAVANDERA, 1984, p. 156). 
ou menos extensamente, e podem se difundir" (LABOV, 2008, p. 20). Esse processo de criação e difusão (ou apagamento) das formas variantes parece ser resultante da pressão que sofre todo sistema linguístico por duas forças potencialmente conflitantes, cujas origens se dão em sociedade. Trata-se de uma tendência mais inovadora e uma mais conservadora. Coseriu (1990) chama essas forças de universais linguísticos básicos de criatividade e alteridade, respectivamente. Enquanto a primeira se responsabilizaria pela variação e a renovação da língua, a segunda se ocuparia da uniformidade no idioma. Assim, na existência das línguas, "a criatividade manifesta-se como renovação das tradições e a alteridade como constância, firmeza e amplitude das tradições idiomáticas"3.

Em suma, é fato que formas linguísticas são criadas a todo instante na língua e, até que essas inovações consigam suplantar - quando é o caso - as forma antigas, verifica-se um estágio no qual tanto a forma inovadora como a antiga coocorrem, isso é, estão em variação. Foi a partir do reconhecimento desse comportamento vívido, criativo e sistemático das línguas que se tornou possível observar que todos os fenômenos linguísticos são organizados por regras categóricas ou variáveis encaixadas no próprio sistema linguístico. Às regras categóricas correspondem os fenômenos não sujeitos à variação, compondo portanto "um conjunto de regras que não podem ser infringidos, sob pena de dificultar ou mesmo inviabilizar a compreensão dos enunciados" (MONTEIRO, 2002, p. 58). As regras variáveis, por sua vez, ocupam-se da escolha de uma forma entre duas ou mais coocorrentes. Atendo-nos mais cuidadosamente em como a Sociolinguística tem procedido ao estudo das

\footnotetext{
"La creatividad se manifiesta como renovación de las tradiciones y la alteridad, como constancia, firmeza y amplitud de las tradiciones idiomáticas" (COSERIU, 1990, p. 55). A partir deste momento, stabele

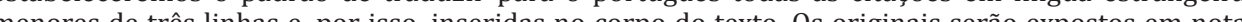
de rodapé.
}

formas gerenciadas pelas regras variáveis, passemos observar o conceito de 'variável linguística'.

Ao lançar os fundamentos da Sociolinguística Variacionista, William Labov desenvolve o conceito de variável linguística tendo em vista fundamentalmente alguns fenômenos fonológicos ${ }^{4}$. Desse modo, para o autor, estaria pressuposta na variação "a opção de dizer 'a mesma coisa' de várias maneiras diferentes, isso é, as variantes são idênticas em valor de verdade ou referencial", opondo-se no que diz respeito ao seu valor social e/ou estilístico (LABOV, 2008, p. 313). O mesmo autor, junto a Weinreich e Herzog, também afirma que as formas coexistentes

Oferecem meios alternativos de dizer "a mesma coisa": ou seja, para cada enunciado em $A$ existe um enunciado correspondente em $B$ que oferece a mesma informação referencial (é sinônimo) e não pode ser diferenciado exceto em termos da significação global que marca o uso de $B$ em contraste com $A$ (WEINREICH, LABOV, HERZOG, 2006, p. 97).

Observemos que, para os autores, a equivalência semântica entre as formas coocorrentes é fundamental. É por isso que, até então, se define o conceito de variável linguística como um grupo de variantes que compartilham um único referente.

De fato, se nos dedicamos a uma análise fonológica da realização do fonema $/ 1 / 5$, nas muitas variedades diatópicas do espanhol, devemos verificar que se empregam, no mesmo contexto, as variantes [j], [dz],[z], [ $\left.\int\right]$, e conforme a variedade observada. Sobre o português, o mesmo se poderia dizer das variantes $[\lambda]$ e [j], representadas pelo grafema ' $l h$ ' nos seguintes contextos: 'alho', 'telha', 'calha'. Em particular ao português, no entanto,

4 A descrição da centralizacão dos ditongos /ay/e /aw/ nas variedades linguísticas de Martha's Vineyard, a realização e a estratificação do /r/ em Nova York, entre outros, são estudos que articulam a noção de variável linguística a partir da observação do âmbito fonológico da língua (LABOV 2008).

5 Representado pelo grafema "Il" nas palavras llave, lleno, lluvia. 
deve-se a que o encaixamento dessa variação fonológica não está limitado apenas a fatores de ordem diatópica, mas também diastrático. Contudo, é comum aos dois exemplos a existência de variantes que compartilham um mesmo referente, ou seja, que corroboram a definição de variável linguística apregoada inicialmente pela Teoria da Variação e Mudança Linguísticas.

É na década de 70 do século passado, entretanto, que o conceito de variável linguística desenvolvido pela recém-instituída Sociolinguística é estendido à análise de fenômenos não-fonológicos, o que gera, conforme comenta Camacho (2010), a primeira grande crise no estatuto metodológico da Teoria Variacionista. Isso porque fora do nível fonológico torna-se difícil definir em que grau as variantes de uma variável são, de fato, diferentes modos de dizer a mesma coisa, isso é, são detentoras do mesmo referente. Melhor descrevendo a questão, Sankoff afirma (1982) que

In turning from phonology to syntax, we encounter a major problem: that of equivalence, i.e. how to ascertain which structures or forms maybe considered variants of each other and in which contexts. This was rarely a problem in phonology since invariance of meaning under substitution of allophones is a widely valid criterion, easy to apply, because it depends only on the recognition of two lexical forms as semantically. [...] This is not the case in syntax. The substitution of different forms often leads to very subtle semantic distinctions, and there is frequently cause for debate as to whether or not there is any change [...] (SANKOFF, 1982, p. 679) ${ }^{6}$.

Foi Lavandera (1978) quem deu início às críticas mais severas sobre a tentativa de ampliar aos outros níveis de análise da língua o conceito de variável linguística desenvolvido com base nos estudos fonológicos. A

6 <Tradução nossa> "Ao passar da fonologia à sintaxe, encontramos um problema maior: o da equivalência, ou seja, como determinar quais estruturas ou formas podem ser consideradas variantes entre si e em quais contextos. Isso raramente era um problema em fonologia uma vez que a invariância do significado quais contis.

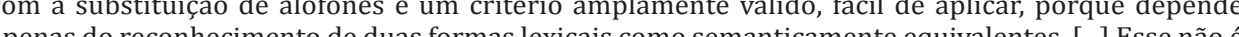

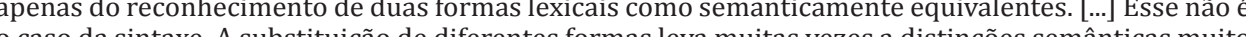
sutis, e há frequentemente motivo para debate sobre se há alguma mudança" (SANKOFF, 1982, p. 679). impropriedade da aplicação, segundo a autora, deve-se a que, na variação não-fonológica, cada uma das possíveis variantes possui um significado referencial particular. Silva-Corvalán (1989), por sua vez, comenta que além de fatores semânticos, fatores de ordem sintática e pragmática também parecem condicionar a variação não-fonológica. Por isso, propôs-se a ampliação da ideia de igualdade semântica para a noção de 'comparabilidade funcional', conceptualização mais abrangente que buscaria no uso da língua uma relação entre as formas em aparente variação.

Labov e Weiner (1983) buscaram avaliar a aplicabilidade do conceito variável linguística desenvolvido no âmbito fonológico à análise sintática. Para tanto, partiram da percepção de que algumas construções na voz passiva e na voz ativa poderiam compartilhar um mesmo referente. Avançados os estudos, chegaram à conclusão de que é necessário especificar o contexto sintático no qual dado fenômeno está em variação com outro. Por isso afirmam que somente entre passivas sem agente e as ativas genéricas seria possível delimitar uma variável sintática, pois manteriam o mesmo significado referencial e o uso de uma ou outra forma estaria determinado por fatores estilísticos.

Segundo Silva-Corvalán (1989), há quatro características que diferenciam a natureza da variação sintática da variação fonológica, a saber:

- Verifica-se menor quantidade de variação sintática que fonológica;

- A variação sintática tende a ser mais difícil de ser estudada e quantificada, já que há pouca frequência de contextos em que ocorre dada variante;

- Os contextos da variação sintática são, no geral, mais difíceis de ser identificados e definidos que os da variável fonológica;

- E, novamente, o estudo da variação sintática torna-se difícil por lidar com possíveis diferenças de sentindo associados a cada uma das variantes. 
Uma vez que a variação não-fonológica não compartilha as mesmas características presentes na variação fonológica, será importante o desenvolvimento de uma nova maneira de proceder ao estudo da variável sintática. Com esse propósito, Labov (1978) mostra que a primeira atividade que deve realizar o pesquisador é a definição e o isolamento de estruturas linguísticas que apresentam comportamentos semelhantes. Aliado a essa etapa, deve-se também definir os contextos em que essas formas ocorrem.

O segundo passo da pesquisa envolveria a observação de contextos em que as duas ou mais formas analisadas (1) compartilham uma mesma função linguística - e que, portanto, estão em variação - ou (2) possuem funções particulares - indicando a existência de regras categóricas. Nas palavras do autor, "a definição de uma variável requer uma séria de passos preliminares destinados à eliminação de todos os contextos em que duas formas alternantes contrastam, isto é, não dizem a mesma coisa"7.

Na mesma direção, Sankoff (1988) sugere que o estudo sistemático da variação não-fonológica também deve ser orientado pela observação do contexto linguístico em que os elementos da língua figuram, isso para que se infiram o significado e a função que os elementos adquirem em dado uso. Para o autor, as particularidades referenciais reservadas a cada uma das formas não-fonológicas podem ser neutralizadas no discurso. Assim, esperase que a conhecimento do comportamento das estruturas linguísticas e dos contextos de neutralização facultem-nos a delimitação da variável linguística. Conforme afirma o autor,

\footnotetext{
"[...] the definition of the variable requires a series of preliminary steps directed at eliminating (in which the two alternant forms constrast, ie do not say the same thing" (LABOV 1978, p. 5).
}

The systematic study of competing forms requires not only the identification of these forms, but also of the individual contexts in which differences between them are neutralized. It is precisely this which constitutes the interpretative component of variationist methodology. The analyst must in effect be able to infer the meaning or function of each token (SANKOFF, 1988, p. 154) ${ }^{8}$.

Não podemos nos desatentar à importância dada no estudo da variação não-fonológica à abordagem qualitativa dos dados. É por isso que se torna imprescindível um conhecimento linguístico e extralinguístico consistente da variedade analisada. Como nos explica Sankoff (1988),

In the more usual situation, the linguistic has to 'know' enough about speech variety and to 'understand' enough about what is transpiring in the particular discourse, to be able to infer speakers' intention. Thus a basically hermeneutic task is combined with more mechanical distributionalist procedures prior to any statistical analysis (SANKOFF, 1988, p. 152) ${ }^{9}$.

Nesse mesmo sentido, Silva-Corvalán (1989) também enfatiza o cuidado que deve envolver a análise das informações quantitativas, isso porque a maior ou menor frequência de uma forma linguística pode estar relacionada às diferenças de significados que possuem, fazendo-a mais ou menos compatível com um contexto comunicativo determinado. A fim de evitar interpretações equivocadas de uma abordagem quantitativa, deve-se, previamente, conduzir a análise por um estudo descritivo atento a fim de definir em quais contextos dada forma lin-

$8<$ Tradução nossa> "O estudo sistemático de formas concorrentes requer não apenas a identificação dessas formas, mas também dos contextos individuais nos quais as diferenças entre elas são neutralizadas. É precisamente isso que constitui a componente interpretativo da metodologia variacionista. 0 analista deve, de fato, ser capaz de inferir o significado ou a função de cada ocorrência" (SANKOFF, 1988, p. 154).

9 <Tradução nossa> "Na situação mais comum a linguística tem de 'saber' o suficiente sobre a variedade falada e 'entender' o suficiente sobre o que está austica ten de 'saber'o suficiente sobre a variedade de inferir a intenção do fantente Assim, uma atividade bapaz

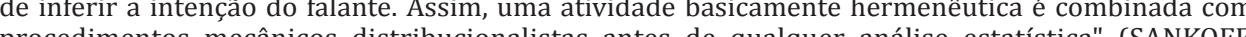
procedimentos mecânicos distribucionalistas antes de qualquer análise estatística" (SANKOFF,
1988, p. 152). 
guística tem sua função igualada à função de outra - também verificada no contexto delimitado. Somente a partir dos pressupostos suscitados por essa delimitação seria possível proceder quantitativamente ao estudo das variantes e, logo, encaixar os resultados estatísticos a variáveis extralinguísticas.

Diante do muito que se há discutido e escrito sobre o tema, parece que a noção de realizações equivalentes - e não a de identidade semântica estrita - é a que melhor se ajusta ao conceito de variável sintática. Isso porque mesmo apresentando um comportamento próprio em determinadas situações, alguns elementos da língua têm suas propriedades neutralizadas no discurso e, por isso, apresentam, em determinados contextos, usos com funções equivalentes. Esses elementos são, portanto, contextualmente alternantes.

Em acréscimo, Serrano (2009, p. 164) assevera que muito mais do que verificar se são ou não sinônimas, em variação sintática, "o objetivo deve se centra em examinar as estruturas alternantes, determinar suas características semântico-discursivo-pragmáticas, o contexto de uso e sua função como ferramenta interativa de comunicação"10.

A segunda parte de nossa discussão estará preocupada em verificar em que medida as reflexões teóricas suscitas até o momento podem nos auxiliar na compreensão da variação na expressão do passado em espanhol.

\section{2 ¿Se me perdió o se me ha perdido? Por uma delimitação da variável linguística}

\author{
Mi unicornio azul ayer se me perdió \\ Pastando lo dejé y desapareció \\ $[\ldots]$ \\ no sé si se me fue, no sé si se extravió \\ $[\ldots]$ \\ Mi unicornio y yo hicimos amistad \\ $[\ldots]$ \\ Mi unicornio azul, se me ha perdido ayer, se fue (SOSA, 2004) ${ }^{11}$.
}

A canção de Silvio Rodriguez, que ressoou na voz de Mercedes Sosa (2004), expõe o pranto de alguém que perde o único e precioso bem que possui: um unicórnio - símbolo da esperança. Num choro inconsolável, esse alguém narra a relação que tinha com o animal, a forma de seu desaparecimento e sua disposição para pagar qualquer preço para tê-lo de volta. Toda narrativa compõem-se com o uso da forma do pretérito perfecto simple (perdió, dejé, desapareció, fue, extravió, hicimos) para fazer referência a situações passadas. Não obstante, saltam aos olhares mais atenciosos a ocorrência da forma ha desaparecido, no pretérito perfecto compuesto, também fazendo menção a uma ação passada. Parece evidente que todos os fatos descritos ocorrem em num mesmo âmbito temporal passado: ayer. Tal semelhança faz-nos pensar na hipótese de se tratar de formas em variação, compondo, portanto, uma variável linguística na expressão do passado absoluto.

A fim de melhor entendermos e, assim, afirmarmos ou negarmos essa e outras variações aparentes no uso das formas do pretérito perfecto,

$11<$ Tradução nossa> "Meu unicórnio azul ontem se perdeu/ pastando o deixei e desapareceu. [...] não se de fugiu ou se se perdeu. [...] Meu unicórnio e eu fizemos amizade. [...] Meu unicórnio azul, se perdeu (de mim) ontem, foi embora" (SOSA, 2004) 10 "El objetivo debe centrarse en examinar las estructuras alternantes, determinar sus características
semántico-discursivo-pragmáticas, el contexto de uso y su función como herramienta interactiva de comunicación" (SERRANO, 2009, p. 164). 
passemos ao estudo das formas simples (PPS) e composta (PPC) ${ }^{12}$. Para tanto, partiremos da descrição feita pela norma-padrão, segundo a qual a cada umas das formas corresponde um uso próprio e categórico, que as diferencia fundamente pela concepção temporal que possuem. Assim, por um lado, encontramos a forma do pretérito perfecto simple (estuve) expressando canonicamente o sentindo de passado absoluto:

(1) La niña que ayer tocó con él "Get Back" y protagonizó uno de los momentos más lindos del recital, habló con varios medios [... ${ }^{13}$.

A menina que ontem tocou com ele "Get Back" e protagonizou um dos momentos mais lindos do show, falou com vários meios de comunicação [...].

Segundo Bello e Cuervo (1954), esse valor significa a anterioridade do atributo ao ato de fala, em outras palavras, trata-se da expressão de um fato anterior à origem (ROJO, 1974), que é o próprio momento de enunciação. No entanto, uma rápida observação do sistema espanhol deve nos mostrar que há outros valores temporais que, de algum modo, também expressam uma anterioridade ao ato de fala ${ }^{14}$. A fim de melhor definirmos os traços do passado absoluto, atentemo-nos ao esboço da expressão da temporalidade verbal no espanhol, proposto por Rojo $(1974,1990)$ :

\footnotetext{
${ }^{12}$ Nossa análise buscou fundamento em enunciados autênticos produzidos principalmente no domínio jornalístico, isto é, pertencentes a artigos de importantes jornais hispânicos e a entrevistas difundidas por rádios argentinas. Esses enunciados fazem parte de um corpus do espanhol compilado especialmente para o estudo da variação diatópica na expressão do passado em espanhol (ARAUJO, 2012a, 2012b 2013 , 2015). Contudo, os fragmentos expostos neste artigo foram cuidadosamente selecionados a fim de promover a discussão que temos em pauta, que visa discutir a delimitação de uma varível da expressão do passado em espanhol.

${ }^{3}$ Enunciado retirado da versão eletrônica do jornal argentino La Nación, de 18/05/2016. Disponível em: <http://www.lanacion.com.ar/1899897-leila-lacaze-sobre-cantar-con-paul-mccartney-me-dio. 18 maio 2016.

${ }^{14}$ Como veremos mais adiante, esse é o caso, por exemplo, do próprio PPC
}

Figura 1 - Da expressão da temporalidade verbal no espanho

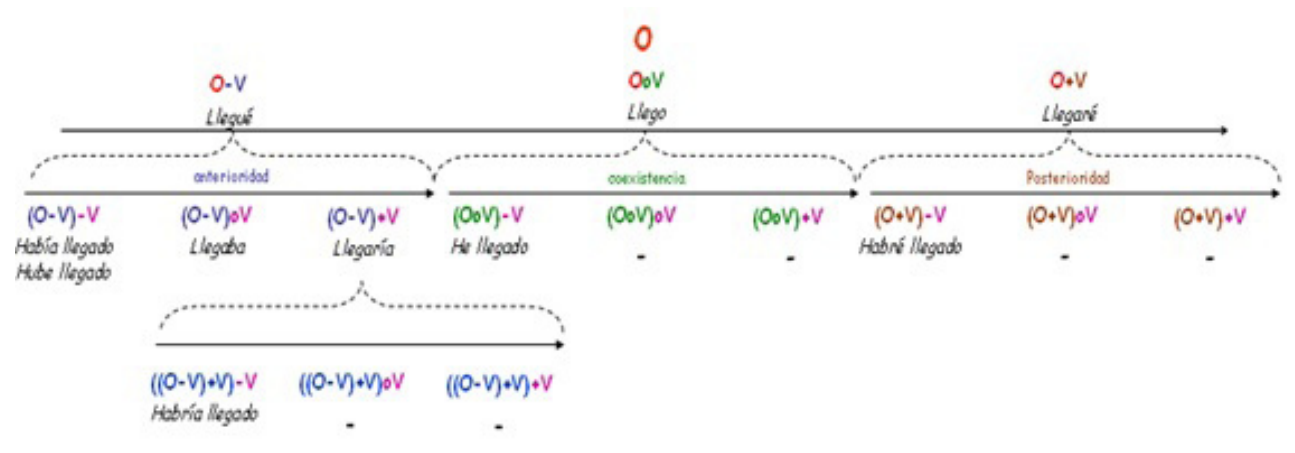

Fonte: Rojo (1974, p. 82) - adaptação nossa.

Observemos que na notação do autor, representa-se a forma llegué por $\mathbf{0}-\mathbf{V}^{\mathbf{1 5}}$. Dado que nos indica que a relação de anterioridade ao momento de enunciação (0), é construída a partir de uma relação direta com 0 - daí decorre o caráter absoluto ${ }^{16}$ que possui o pretérito perfecto simple (PPS) quando expressando o valor passado absoluto (ROJO, 1999). Ainda analisando o comportamento dessa forma verbal, porém já com vistas à observação da forma composta, Cartagena (1999) explica-nos que o PPS, da mesma maneira que as demais formas de valor temporal absoluto, delineia, a partir do ponto zero, um segmento temporal primário. Assim,

${ }^{15}$ 'O' significa 'ponto zero' ou 'ponto central', isso é, o momento que serve como referência para a estruturação de todo o sistema temporal da língua. Segundo Benveniste (2006), esse seria o momento de enunciação. "V", por sua vez, significa 'vetor' isso é, o momento do próprio evento, o qual, por sua vez, se estrutura, em relação ao ponto zero $(\mathbf{0})$, como anterior $(-)$, concomitante $(\mathbf{o})$ ou posterior $(+)$. ${ }_{16}$ Rojo (1999) chama de absoluto as relaç̃es temporais que se estruturam em relação direta $(+0 m$ ponto zero/central, ou seja, o'passado absoluto' ( $\mathbf{0}-\mathbf{V})$, o 'presente' $(\mathbf{O o V})$ e o 'futuro' $(\mathbf{0}+\mathbf{V})$. Por sua ponto zero/central, ou seja, o passado absoluto $(\mathbf{O}-\mathbf{V})$, o presente $(\mathbf{O o V})$ e o futuro' $(\mathbf{O}+\mathbf{V})$. Por sua mas com uma referência secundária - que, por sua vez traçáa relação com o ponto central. Esse é, mas com una referencia sectérín pia - que, por sua vez, traç $((\mathbf{O o V})-\mathrm{V})$. 
[...] el presente marca la coexistencia [ámbito primario de coexistencia], el paralelismo del hablar con un punto del tiempo real, respecto del cual las formas de pretérito perfecto simple y de futuro indican anterioridad [ámbito primario de retrospectividad] y posterioridad [ámbito primario de prospectividad], respectivamente (CARTAGENA, 1999, p. 2937) ${ }^{17}$.

Notemos que a atribuição do sentido de passado absoluto ao PPS deve-se a que essa forma verbal assume como referência a envoltura temporal que abarca aquilo que já não faz parte do presente, mas que pertence ao âmbito primário de retrospectividade. De modo mais prático, a observação dos enunciados que seguem deve nos mostrar eventos envolvidos por essa concepção temporal:

(2) [...] ayer hablé con los periodistas [...].18 $[\ldots]$ ontem falei com os jornalistas [...]

(3) El año pasado estuve haciendo la consigna de Arnold. ${ }^{19}$ $\mathrm{O}$ ano passado estive fazendo a proposta do Arnold Wesker.

Destacamos o papel dos marcadores discursivo $\mathrm{s}^{20}$ em ressaltar o sentido aportado pela forma verbal. Isso porque ao dizer 'ayer' ou 'el año pasado', indica-se a abrangência do 'âmbito primário de restrospectividade’ referido. Em outras palavras, ao usar esses marcadores destaca-se que a situação

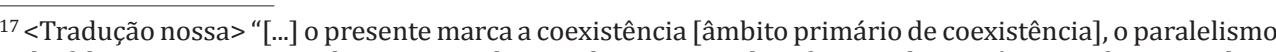
do falar com um ponto do tempo real, em relação ao qual as formas do pretérito perfecto simples e de futuro indicam anterioridade [âmbito primário de retrospectividade] e posterioridade [âmbito primário de prospectividade], respectivamente" (CARTAGENA, 1999, p. 2937)

${ }^{18}$ Enunciado retirado de uma entrevista radiofônica difundida pela rádio Cadena 3, de Córdoba/Argentina $(13 / 06 / 2010)$

${ }^{19}$ Enunciado retirado de uma entrevista radiofônica difundida pela rádio Palermo, de Buenos Aires/ Argentina (29/09/2010).

${ }^{20}$ Recorrentemente, fazemos uso dos termos 'marcador temporal' para referir ao conjunto de expressões disponíveis na língua e que marcam, de algum modo, uma percepção de tempo. Ou seja, além dos advérbios e locuções adverbiais de tempo, incluímos também nesse grupo sintagmas nominais ("en los juegos olímpicos, en la dictadura") e orações subordinadas ("cuando quiso trabajar no lo dejaron") que auxiliam na construção da referência temporal expressa no enunciado (MARTíNEZ GARCÍA, 2003).
}

descrita já não faz parte do 'âmbito de coexistência' - 'hoje' e 'neste ano', respectivamente. É nesse sentido que Alarcos Llorach (1972, p. 25) aponta o uso do PPS com os advérbios que indicam que a ação produz-se num período de tempo no qual não está incluído o momento presente da fala. Essa breve descrição do valor de 'passado absoluto' tende a adquirir maior clareza a partir do estudo do pretérito perfecto compuesto - forma a que se associa canonicamente o valor de antepresente:

(4) La ópera prima del director indio ha ganado hoy la Butaca de oro del Premio Principado de Asturias [...]..$^{21}$

A ópera prima do diretor indiano ganhou hoje a poltrona de ouro do Prêmio Príncipe de Astúrias.

Nesse sentido, Cartagena (1999) mostra-nos que as formas compostas por 'haber+particípio' apresentam um comportamento semelhante às formas simples absolutas, pois criam fragmentos temporais secundários de perspectiva retrospectiva em cada um dos âmbitos primários instaurados pelas formas simples. Ou seja, as estruturas compostas não guardam relação direta com o momento de enunciação, mas com as referências instauradas pelas formas simples. Assim, “[...] He hecho, hube hecho, habré hecho indicam anterioridade [...] em relação ao ponto central de cada âmbito temporal gerado pelas formas simples, apareça este, ou não, expressamente referido nos textos" (CARTAGENA, 1999, p. 2937) ${ }^{22}$.

Diante da síntese da descrição gramatical, conseguimos averiguar como se instaura o 'antepresente' na forma do Pretérito Perfecto Compuesto: um valor relativo de anterioridade (em um âmbito secundário) ao presente, que

${ }^{21}$ Enunciado coletado do jornal El País, de 29/11/2014. Disponível em: <http://cultura.elpais.com/ cultura/2014/11/29/actualidad/1417288689_075919.html>. Acesso em: 16 maio 2016

22 “[ ] He hecho hube hecho habré hecho indican [ ] anterioridad, pero en relación con el punto central [...] He hecho, hube hecho, habré hecho indican [...] anterioridad, pero en relación con el punto central los textos". (CARTAGENA, 1999, p. 2939). 
lhe serve de referência dentro do âmbito primário. Reparemos que tanto o evento descrito quanto a referência no presente estão contidas no 'âmbito primário de coexistência' ao momento de fala.

Esse sentido fica melhor apreciado por meio da reprodução da Fig. 2, na qual se expõe parte das formas verbais do indicativo (CARTAGENA, 1999, p. 2938). Em destaque, o pretérito perfecto compuesto representa a expressão de uma anterioridade (no âmbito secundário), que está contida no 'âmbito primário de coexistência' (APco) ${ }^{23}$.

Figura 2 - Do tempus nas formas verbais do indicativo

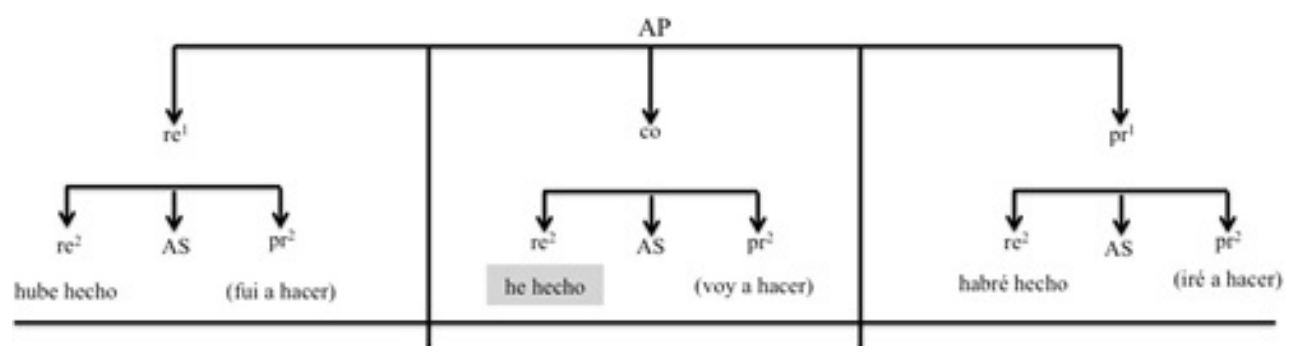

Fonte: Cartagena (1999, p. 2938) - adaptação nossa.

Desse modo, diferentemente da forma do PPS (hice), canonicamente responsável pela expressão de situações pretéritas envolvidas por um 'âmbito primário de anterioridade', com o perfecto compuesto (he hecho), apresentase canonicamente um evento passado envolvido por uma percepção de presente ('âmbito primário de coexistência') e que, por isso, guarda uma relação temporal de coexistência com o momento da fala ('antepresente'). Diante dessa descrição, Cartagena (1999, p. 2941) resume o uso do PPC

${ }^{23} \mathrm{Na}$ Fig 2, AP quer dizer Âmbito Primário; AS, Âmbito Secundário e RE, CO e PR, respectivamente, REtrospectividade, COexistência e Prospectividade. com este valor afirmando que sua função é "indicar que uma ação se realiza antes de um ponto zero que nos serve de referência para medir o tempo, mas dentro do âmbito que tem como centro a coexistência ou a simultaneidade de tal ponto com o momento de fala" 24

A fim de melhor entender o valor de 'antepresente', muitos autores valem-se da observação de elementos linguísticos recorrentes no contexto de uso da forma composta. Assim, apontam o uso do PPC de antepresente "com os advérbios que indicam que a ação se deu em um período de tempo no qual se encontra compreendido o momento presente do que fala ou escreve"; tal seria o caso de hoje, agora, estes dias, esta manhã, este mês, o ano em curso, atualmente, na minha vida, durante o presente século, etc (ALARCOS LLORACH, 1972, p. 24).

Observemos que com qualquer uma dessas expressões conseguimos envolver em um mesmo âmbito temporal (de coexistência) tanto a situação descrita como o momento de fala. Ou seja, ao dizermos:

(5a) Ha ganado hoy el auto de su sueño. Ganhou hoje o carro de seu sonho.

(5b) Ha ganado este año el auto de su sueño. Ganhou este ano o carro de seu sonho.

consideramos que tanto o acontecimento ganhar el auto ('ganhar') como o momento da fala estão contidos na mesma envoltura temporal: 'hoy' (hoje) ou 'este año' (este ano), respectivamente. Em complemento, a Nueva gramática de la lengua española (RAE, 2009, p.1722 e 1723) explica que o valor de antepresente coincide temporalmente, entre outros, com:

${ }^{24}$ [...] indicar que una acción se realiza antes del punto cero que nos sirve de referencia para medir el tiempo pero dentro del ámbito que tiene como centro la coexistencia o simultaneidad del dicho punto con el momento del habla (CARTAGENA, 1999, p. 2941). 
a. Demostrativo este: "En este siglo la ciencia ha experimentado grandes avances" ("Neste século a ciência experimentou grande avanços"). Em oposição ao demonstrativo aquel, que indicaria um âmbito primário de anterioridade e, por isso, associado ao uso do PPS: "En aquel siglo la ciência experimentó grandes avances".

b. Adjetivo actual: "En su actual situación laboral, ha sufrido no pocos sinsabores" ("Em sua atual situação de trabalho, não foram poucos os disapobres sofridos"). Em oposição ao adjetivo anterior, que indicaria um âmbito primário de anterioridade e, por isso, associado ao uso do pretérito perfecto simple.

c. Adjetivo presente: "La vicetiple ha tenido días me jores en la presente temporada" ("A corista teve dias melhores na presente temporada").

Alarcos Llorach (1972) explica-nos também que mesmo em enunciados de sentido 'antepresente' sem uso de marcadores temporais pode-se observar implicitamente a consciência do falante de que os eventos têm como limite o presente gramatical. Nesses casos, infere-se o especificador: 'neste período de tempo em que falamos'.

A síntese da descrição gramatical do PPS e do PPC deve nos mostrar regras categóricas no uso de cada uma das formas, isso porque, conforme nos explicam esses materiais, a cada uma das formas se associam um valor próprio: 'passado absoluto' e 'antepresente', respectivamente. Em outras palavras, se a situação pretérita ocorre em uma concepção temporal que já não é a mesma do ato de fala, observa-se a expressão do valor de 'passado absoluto' (V-0) - PPS. Por sua vez, se a situação passada é relativa e envolta pela mesma concepção temporal que abarca o momento de enunciação, temse a expressão do 'antepresente' ((Vo0)-V) - PPC.

No entanto, devido à pequena nuança de significado que diferencia ambos os valores, parece ser provável que as formas que canonicamente foram descritas como portadoras dos respectivos sentidos se entrecruzem e passem a expressar o sentido da outra. Além disso, é necessário tomar consciência da existência de mais valores associados ao PPC e ao PPS ${ }^{25}$. De fato, a observação empírica da expressão desses valores tem acusado um estado bastante heterogêneo do uso das formas compostas e simples do pretérito perfecto sob as mais diversas perspectivas de análise da variação (diacrônica, diafásica, diastrática, diatópica).

Atendo-nos fundamentalmente ao caráter dialetal da variação existente entre o uso do perfecto simple e o perfecto compuesto quando detentores dos sentidos em pauta e nos dirigindo à observação, a princípio, dos estudos sobre as variedades peninsulares, verificamos em manuais "consagrados" sobre a língua espanhola a tendência em opor Galicia e Asturias às demais comunidades autônomas da Espanha. Segundo essa norma tradicional, se observaria o predomínio da forma simples nas regiões citadas e o predomínio da forma composta nas demais. Cartagena (1999), por sua vez, assume uma postura extremamente generalizadora ao afirmar ser possível observar a oposição PPS/PPC, na mesma proporção, ao longo de toda a Península. Em comum, tais abordagens procedem ao estudo das formas do pretérito perfecto desconsiderando os diferentes valores que poderiam se associar às formas e, por isso, cometem o erro de proceder ao estudo da variação sem considerar, primeiro, os sentidos e contextos comuns de uso.

Há ainda outros trabalhos que adotam a abordagem generalizadora para o território peninsular (GUTIÉRREZ ARAUS, 2001; MORENO DE ALBA, 2000; COMPANY COMPANY, 2002; HOWE; SCHWENTER, 2003). No entanto, contrariando os anteriores, aportam algumas informações relevantes no que diz respeito aos valores atribuídos ao pretérito perfecto. Assim, os três

${ }^{25} \mathrm{~A}$ título de exemplo, o estudo dos valores atribuídos ao PPC nas variedades dialetais da Argentina (ARAUJO, 2012a, 2013) mostrou a existência de pelo menos sete valores associados à forma composta: antepresente, passado imediato, resultado, experiencial, persistência, passado absoluto e antepretérito. 
primeiros pesquisadores observam o valor de antepresente no uso peninsular da forma composta. Seguindo a mesma tendência, Howe e Schwenter (2003) observam o crescente uso do pretérito perfecto compuesto abarcando, inclusive, valores temporais que outrora cabia ao perfecto simple expressar (passado absoluto). Daqui se poderia pressupor, portanto, a aparente existência de uma regra variável para a expressão do passado absoluto, na qual tanto o PPC e o PPS seriam formas possíveis.

Entre os mais atentos à variação dialetal dentro da península e evitando conclusões generalizadoras de uso, figuram os trabalhos de Kany (1969) e Hurtado González (1998), por exemplo. O primeiro deles aponta a possibilidade de encontrarmos o PPC expressando o valor de antepresente em Navarra, Aragón e parte de Castilla la Vieja, ao passo que na Galicia, notar-se-ia mais correntemente o uso do PPS expressando esse sentido isso é, tanto o PPS como o PPC seriam variantes da expressão do valor de antepresente na variedade galega. Finalmente, o autor também observou em Madri o uso da forma composta expressando passado absoluto, mostrandonos, por isso, que a norma da capital espanhola prevê uma regra variável para a expressão do passado absoluto.

A fim de esboçarmos mais um exemplo e procurando evitar o risco de nos perdermos em generalizações, decidimos por observar a realização o uso do PPC e do PPS na Argentina. Assim, observamos que os trabalhos de maior repercussão sobre as formas do pretérito perfecto na Argentina desenvolveram-se tendo em vista, fundamentalmente, às variedades bonaerense e noroeste. Conforme os interesses desses estudos, percebemos dois tipos de abordagens: (i) uma preocupada exclusivamente com a norma linguística de alguma(s) das regiões argentinas e (ii) outra interessada em descrever a manifestação das formas do pretérito perfecto na América e que, para tanto, apresenta brevemente a situação dos pretéritos na Argentina.
Atentando-nos inicialmente a essa última abordagem, observamos que trabalhos como os de Gili Gaya (1970), RAE (1986), Oliveira (2007) afirmam a existência de um uso comum para todo o país - no qual predominaria a forma do PPS. Não obstante, a conclusão tida pelos autores sobre o comportamento do pretérito perfecto parece decorrer da generalização do uso observado na norma bonaerense. Por outro lado, uma segunda postura, que opõe o comportamento do pretérito perfecto na região norte ao comportamento na região bonaerense, pode ser observada em trabalhos desenvolvidos por Kany (1969), Gutiérrez Araus (2001), Alarcos Llorach (2005) e Jara Yupanqui (2009). Nessa direção, Gutiérrez Araus (2001, s/n) afirma que

[...] el panorama de uso de las formas canté/he cantado en este gran país es variado y aparecen dos zonas claramente diferenciadas al respecto: por un lado el norte del país: Tucumán, Salta, etc. y por otra parte, Buenos Aires y el Litoral (GUTIÉRREZ ARAUS, 2001, s/n) ${ }^{26}$.

Soma-se a essa proposta de bipartição, a observação do maior índice de ocorrência do PPS sobre o PPC na área do Río de la Plata e um crescente uso do PPC à medida que nos dirigimos ao noroeste do país. Destacamos que muitas dessas afirmações são feitas sem a exposição dos valores atribuídos às formas, de modo a dificultar a exata definição da(s) variável(is). De encontro a essas posturas, Gutiérrez Araus (2001), baseando-se no estudo de Kubarth (1992), faz-nos saber que, apesar da significativa diminuição do uso do PPC em Buenos Aires, ainda se trata de uma forma viva dentro dessa zona. Não obstante, há de se observar que ela já

${ }^{26}<$ Tradução nossa> "[...] o panorama de uso das formas canté/he cantado neste grande país é variado e aparecem duas zonas claramente diferenciadas em relação ao assunto: por um lado, o norte do país: Tucumán, Salta, etc. e, por outra parte, Buenos Aires e o Litoral” (GUTIÉRREZ ARAUS, $2001, \mathrm{~s} / \mathrm{n})$. 
[...] no funciona como forma de anterioridad inmediata a la enunciación o antepresente, como tampoco se emplea en momentos culminantes o emotivos de la narración o enfatizador, sin embargo sí se emplea como forma resultativa con relevancia del presente (GUTIÉRREZ ARAUS, 2001, s/n) ${ }^{27}$.

Notemos que nessa variedade, o valor antepresente já não parece ser o principal valor atribuído à forma composta, mas sim o valor 'resultativo', que, conforme acusam alguns estudos sobre aspecto verbal, pode estar relacionado ao aspecto 'perfeito', que estaria associado à forma composta (COMRIE, 1976; CARTAGENA, 1999; COMPANY COMPANY, 2002; GARCÍA FERNÁNDEZ, 2008) ${ }^{28}$. Frente a essa informação, alertamos ao risco de não realizar uma prévia abordagem qualitativa na análise das ocorrências do PPC e do PPS, isso porque os casos próprios do PPC, em que figura o valor resultativo, podem ser considerados formas equivalentes ao PPS.

Sobre a região noroeste do país, por outro lado, a RAE (2009) destaca a maior incidência da PPC, expressando inclusive o valor temporal de passado absoluto - indício de que na região vigoraria uma regra variável na expressão dessa concepção temporal. Observando mais atentamente o comportamento da forma composta nas regiões dialetais da Argentina (ARAUJO, 2012a, $2013)^{29}$, verificamos que o uso com o valor de antepresente corresponde a $25 \%$ (19 casos) da quantidade total de casos do PPC encontrados no corpus da região noroeste, ao passo que no corpus da região bonaerense não foi encontrado nenhum caso em que se marcava a expressão desse valor. Em relação ao passado absoluto, contrariando o comportamento tido como

$27<$ Tradução nossa> "[...] não funciona como forma de anterioridade imediata à enunciação ou antepresente, como também não se emprega em momentos culminantes ou emotivos da narração ou com valor enfatizador, no entanto, sím, se emprega como forma resultativo com relevância do presente" (GUTIÉRREZ ARAUS, 2001, s/n).

posterior ao tempo da situação descrita, mostrando-nos, por isso, seus resultados.

${ }_{29}$ No estudo realizado, foram aferidos junto ao PPC os valores de antepresente, passado recente, resultativo, experiencial, persistência, passado absoluto e antepretérito. canônico, foi possível observar a relevância de seu uso para ambos os corpora ( $15 \%$ dos casos na região bonaerense e $25 \%$ dos casos na região noroeste).

Por não estar inserido nos objetivos do trabalho recém-comentado (ARAUJO, 2012a), como tampouco em outros estudos verificados, não se sabe precisamente quais valores são atribuídos à forma do PPS frente ao comportamento do PPC nas variedades argentinas analisadas.

Respeitando as limitações e generalizações dos estudos apresentados, parece que, conforme a variedade diatópica analisada, as formas do pretérito perfecto podem funcionar como variantes na expressão de um dos valores de passado que discutimos. Isso é assim porque a maior parte desses estudos está limitada à análise de questões temporais, muitas vezes, sequer explicitadas. Da mesma maneira, se nos limitamos ao âmbito da temporalidade, é possível observar em algumas variedades dialetais da Argentina a neutralização das particularidades das formas do pretérito perfecto, de modo que encontramos, na variedade patagônica, por exemplo, formas verbais que expressam o valor de antepresente - canonicamente associado ao PPC.

(6) Hoy se han escuchado algunas voces de los representantes de las asociaciones de taxista[...]. ${ }^{30}$

Hoje se escutaram algumas vozes dos representantes das associações de taxista [...].

(7) El hicha de Huracán posó por esta mañana de hoy. ${ }^{31}$ O torcedor do Huracán passou nesta manhã de hoje.

É de se esperar que o estudo dos fatores extralingüísticos ofereça uma resposta que justifique a variação no uso das formas que aparentemente

${ }^{30}$ Enunciado retirado de uma entrevista radiofônica difundida pela rádio Plus 10, de Comodoro Rivadavia Argentina (12/10/2010).

entrevista radiofônica difundida pela rádio Cadena 3, de Comodoro Rivadavia, Argentina (12/10/2010). 
expressam um mesmo valor temporal - ações ocorridas no antepresente (hoy). Da mesma maneira, a observação do valor de passado absoluto nos enunciados abaixo mostra-nos que, no que cabe à temporalidade, as formas também são coocorrentes, na variedade central, já que igualmente retratam eventos ocorridos no passado absoluto (ayer)

(8) [...] ayer hablé con los periodistas [...]..$^{32}$ [...] ontem falei com os jornalistas [...]

(9) Ayer ha habido algo diferente en la escena política argentina. ${ }^{33}$ Ontem houve algo difente na cena política argentina.

Não obstante, antes de qualquer afirmação que afirme as aparentes variações mencionadas, devemos refletir sobre uma nova postura investigativa do pretérito perfecto, especificamente sobre as variedades argentinas. Orientados por essa nova perspectiva, passa-se a inserir ao quadro de análise questões de ordem aspectual e, desse modo, possibilita-se descrever o uso do pretérito perfecto compuesto expressando valores não previstos pela abordagem tradicional - como vimos, calcada fundamentalmente em questões exclusivamente temporais. Graças à nova abordagem, é possível proceder melhor ao estudo do uso de ambas as formas, delimitando situações em que, de fato, elas compõem regra(s) variável(is) e situações em que operam de forma categórica.

A fim de nos valermos da contribuição aportada pelo estudo do aspecto perfeito $^{34}$, voltamo-nos à letra da canção que nos serviu de mote e, assim,

${ }^{32}$ Enunciado retirado de uma entrevista radiofônica difundida pela rádio Cadena 3, de Córdoba/Argentina $(13 / 06 / 2010)$

${ }^{33}$ Idem.

${ }^{34} \mathrm{Na}$ classe aspectual de 'perfeito', o foco volta-se ao momento que está imediatamente posterior ao tempo da situação, mostrando-nos, por isso, os resultados da situação ou, em outras palavras, a relevância presente de uma situação concluída. É consciente desse valor que Comrie (1976) afirma que o perfeito não nos diz nada diretamente sobre a situação em si, mas relata alguns estados de uma situação precedente. questionamo-nos se de fato verificamos nela uma variável linguística na expressão da mesma concepção temporal de passado. Se pressupusermos que sim e que um único falante seria responsável por sua enunciação, devemos então nos questionar sobre a razão que motivaria a seleção de uma forma do pretérito perfecto em detrimento da outra uma única vez.

Por nossa parte, defendemos que nem sempre constituem uma variável linguística. Para melhor explicá-la, no entanto, é importante recorrermos ao estudo do aspecto verbal. Segundo Comrie (1976), Cartagena (1999) e García Fernández (2008), em enunciados em que figuram o PPS observa-se a marcação do aspecto 'perfectivo', o que implica a contemplação completa da situação descrita, isso porque a "perfectividade indica o ponto de vista de uma situação como um todo único, sem distinção das várias fases que compõem essa situação ${ }^{35}$. Desse modo, ao se dizer

(10) Mi unicornio azul ayer se me perdió (SOSA, 2004), Meu unicórnio azul ontem se perdeu de mim.

observamos uma ação (perder) que teve seu início, desenvolvimento e conclusão já terminados e não oferece nenhuma informação para além do âmbito em que ocorre.

Por sua vez, os mesmos autores observam em enunciados em que figuram formas do PPC a possibilidade de se marcar o aspecto perfecto. Em consequência, enunciados desse tipo possibilitam marcar a relevância presente da situação passada descrita (PPC). Isso é assim porque nessa classe aspectual, o foco volta-se ao momento que está imediatamente posterior ao término da situação, mostrando-nos, por isso, seus resultados. É consciente

"[..] perfectivity indicates the view of a situation as a single whole, without distinction of the various separate phases that make up that situation." (COMRIE, 1976, p. 16). 
deste valor que Comrie (1976, p. 52) afirma que o perfeito "não nos diz nada diretamente sobre a situação em si, mas relata alguns estados de uma situação precedente ${ }^{36 "}$. Desse modo, ao se dizer:

(11) Mi unicornio azul, se me ha perdido ayer. (SOSA, 2004), Meu unicórnio azul, se perdeu de mim ontem.

busca-se salientar que ainda no presente se sofre com a perda do animal. De modo mais evidente, essa tentativa de enfatizar a dor que sofre o eu-lírico com a perda é também salientado com o uso do pronome me (se me perdió/ se me ha perdido) com função de dativo ético ${ }^{37}$. Função que, segundo Berlinck (1996, p. 147), é limitada à primeira e segunda pessoas e expressa por um clítico. Ainda segundo a autora, seu uso ocorre em sentenças marcadas emocionalmente e ajuda a enaltecer a intensidade do envolvimento emocional do falante (ou ouvinte) em relação ao que está sendo dito.

Atentemo-nos, portanto, às escolhas linguísticas (pretérito perfecto compuesto, 'pronomes clíticos') feitas pelo enunciador com a finalidade de tecer um texto em que o pranto decorrente de uma perda transpire por cada palavra enunciada. Não obstante, um leitor mais questionador poderia dizer que se trata de um uso muito particular da forma composta, restrito ao registro literário ou a situações solenes. No entanto, a observação da modalidade oral das variedades dialetais argentinas, em situação mais espontânea (entrevistas radiofônicas), também acusa o uso do PPC e do PPS em condições aparentemente categóricas.

36 "The perfect [...] tells us nothing directly about the situation in itself but rather relates some states to a preceding situation" (COMRIE, 1976, p. 52).

37 Segundo explica a RAE (2009 p. 2657), os dativos éticos permitem integrar no verbo um elemento distante a ele, mas que é a fetado, em alguma medida, pela noç̃o expressa no predicado. Em cistante a le, a RA qu
A título de exemplo, vejamos como ambas as formas coocorrem em enunciados cujo âmbito temporal é um único:

(12) Sí, sí. La verdad que hay mucha expectativa es decir, con alegría hemos jugado ya dos partidos del [superseis] que se realizó allí en nueve de Julio, en Río Tercero, y un amistoso unos días atrás en Oncativo. ${ }^{38}$

Sim, sim. A verdade é que há muita expectativa, ou seja, com alegria já jogamos duas partidas do super-seis, que se realizou lá, nove de julho, em Río Tercero, e um amistoso, uns dias atrás, em Oncativo.

(13) Si bien le costó a Velez Sarsfield y mucho ganarle a Argentino Junior. Pero también, junto con River, ha ganado sus tres partidos y de esta manera es uno de los punteros que tiene el campeonato apertura de primera división. ${ }^{39}$

Apesar de ter custado ao Velez Sarsfield, e muito, ganhar do Argentino Junior. Mas também, junto ao River, ganhou suas tres partidas e, dessa maneira, é um dos pontas que tem o campeonato de abertura da primeira divisão.

(14) [...] yo prácticamente me he criado en el Teatro Avenida, luego dirigí espectáculo de café con sed y de niños [...].40

[...] eu praticamente me criei no Teatro Avenida, por isso dirigi espetáculo de "Café com Sede" e de crianças [...].

(15) [...] ustedes saben cuando yo me hice cargo del PAMI, hace aproximadamente un ano y medio, [...] yo he recibido el padrón de seis mil afiliados y a la fecha tenemos un padrón de ciento treinta mil afiliados. ${ }^{41}$

[...] vocês sabem quando eu me encarguei do PAMI, faz aproximadamente um ano e meio, [...] eu recebi o cadastro de cento e trinta mil afiliados e atualmente temos um cadastro de cento e trinta mil afiliados.

${ }^{38}$ Enunciado retirado de uma entrevista radiofônica difundida pela rádio Cadena 3, de Córdoba/Argentina

$(22 / 09 / 2010)$.
${ }^{39}$ Enunciado retirado de uma entrevista radiofônica difundida pela rádio LV10, de Mendoza/Argentina $(25 / 08 / 2010)$

${ }^{40}$ Enunciado retirado de uma entrevista radiofônica difundida pela rádio Palermo, de Buenos Aires/ Argentina $(29 / 09 / 2010)$.

41 Entrevista radiofônica difundida pela rádio LV7, de San Miguel de Tucumán/ Argentina $(30 / 11 / 2010)$. 
Semelhante à canção introdutória, esses enunciados possibilitam-nos refletir sobre fatores que acarretariam a alternância entre as formas do pretérito perfecto. Seriam fatores de ordem extralinguística que definiriam a escolha de uma ou outra variante, sem que, para isso, houvesse alternância de significado? Mas como definir quais são esses fatores, já que se trata de um único enunciador produzindo um enunciado sob as mesmas condições extralingüísticas? Por outro lado, podemos encontrar na marcação aspectual o fator diferenciador da função e, logo, do uso das duas formas verbais.

Direcionando nossa atenção ao enunciado (12) e aplicando-lhe as duas hipóteses de análise, observaremos, primeiramente, que tanto a forma composta ('hemos jugado') como a simples ('realizó') apresentam uma mesma concepção temporal, isso é, ambas descrevem uma situação que ocorreu em um âmbito temporal anterior ('unos días atrás') ao âmbito temporal que envolve a enunciação. De modo mais objetivo, tanto o PPS como o PPC possuem o valor de passado absoluto $(0-\mathrm{V})$, constituindo, por tanto, uma variável na expressão do tempo em questão.

Não obstante, uma abordagem que considere a contribuição aspectual para a compreensão do enunciado perceberá facilmente que não se trata de formas variantes, mas sim de formas que possuem usos categóricos. Isso é assim porque o aspecto perfeito, presente em 'hemos jugado', diferencia a forma composta da simples ("realizó"). Mais especificamente, com o uso da forma composta marca-se a relevância presente de uma ação pretérita (jugar), criando, no momento de enunciação do fragmento (12), uma atmosfera de 'mucha expectativa'. Por outro lado, a forma simples 'realizó' pouco contribui para essa realidade descrita no momento da fala. Isso porque o aspecto perfectivo, presente no PPS, fixa-se na observação do momento final do evento pretérito (realizar), despreocupando-se em apresentar a relação direta que essa situação guarda com o ato de fala.
Algo semelhante se poderia dizer do enunciado (13), no qual, por meio da forma composta ha ganado, enfatiza-se que a já ocorrida vitória do time Velez Sarsfield nos três jogos do campeonado argentino de futebol mostra-se relevante no momento presente em que se encontra o enunciador quem, por isso, diferencia-o dos demais clubes por ser o líder (puntero) no campeonato. Na mesma direção, o uso do PPC no enunciado (14) (he criado) auxilia na ânfase dada à familiariade do enunciador com o Teatro Avenida, o que lhe resula na direção de alguns espetáculos.

Finalmente, no enunciado (15), observamos tanto a forma hice como he recebido fazendo referência a eventos ocorridos num contexto temporal de passado absoluto. Se por uma abordagem restrita ao estudo da concepção temporal teríamos uma regra variável para a expressão do passado absoluto, conduzidos pelo estudo aspectual, diferenciaríamos o PPC do PPS, porque enquanto este deixa limitado os eventos (hice) à concepção temporal passada, aquele possibilita relacionar ação passada (he recebido) com o momento presente da enunciação, no qual se verifica o crescimento numérico de afiliados. Logo, parece que o enunciador recorre ao uso da forma composta para ressaltar a relevância do trabalho que começou a desenvolver quando assumiu o cargo. A Figura 3 ilustra como a relevância presente pode se dar também no uso do PPC com valor de passado absoluto, isso porque o 'tempo de foco' (lente) atem-se às consequências da situação passada no momento de fala (MF). 
Figura 3 - Do valor de passado absoluto com relevância presente

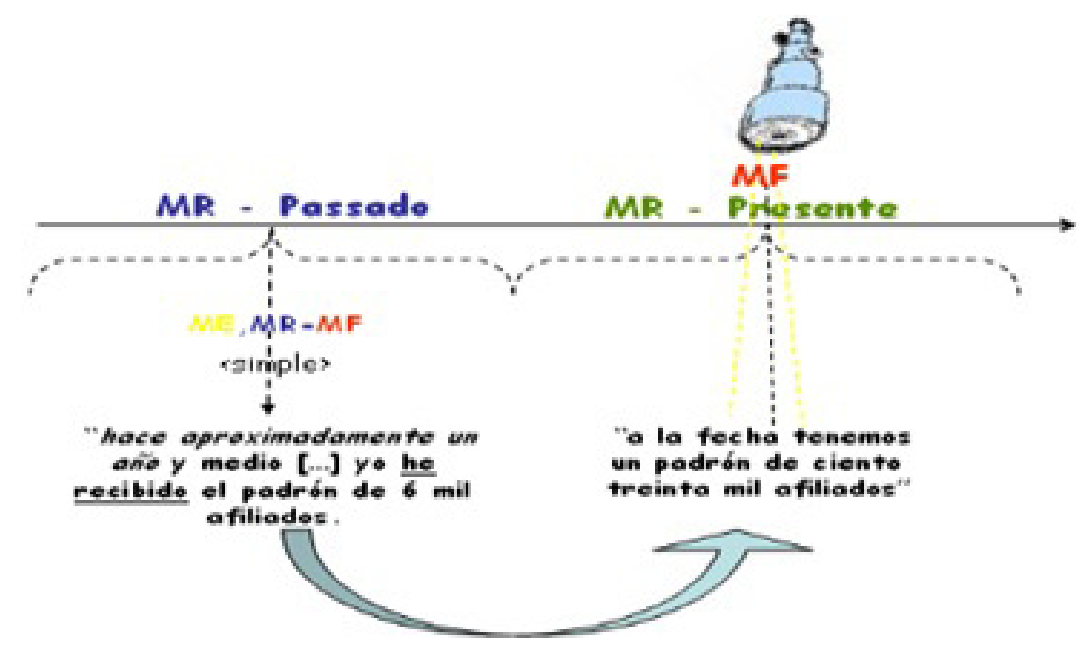

Fonte: Autor (2017).

\section{Considerações finais}

Para concluirmos, não pretendemos afirmar, por meio deste trabalho, a inexistência de ocorrências em que se verifica variação no uso do pretérito perfecto simple e do pretérito perfecto compuesto. De fato, as abordagens mais atentas à pertinência do traço aspectual no uso do PPC, mostram que em algumas variedades peninsulares, por exemplo, o traço aspectual não parece diferenciar as formas e, por isso, observa-se o PPC e o PPS como variantes na expressão dos valores de antepresente e/ou passado absoluto. Nossa intenção é, portanto, chamar atenção ao risco de incluir num mesmo conjunto de variantes casos em que não se verifica variação. Acreditamos que informações contextuais e o valor que possui cada forma devem ser avaliados cuidadosamente antes da definição das variáveis linguísticas.
Isso porque, a nosso ver, um estudo que procure comprovar a existência de variação entre essas formas deverá ocorrer somente entre as situações de uso que expressam o mesmo valor, isso é, em que tenham as particularidades neutralizadas no discurso (SANKOFF, 1988). Por fim, destacamos ainda a atenção que se deve ter com a diversidade espacial, haja vista que todos os estudos apontados indicam que a variável diatópica é relevante para a correta compreensão do fenômeno.

\section{Referências}

ALARCOS LLORACH, Emilio. Perfecto simple y compuesto. In: ALARCOS LLORACH, E. Estudios de gramática funcional del español. Madrid: Gredos, 1972. p. 13-49.

ALARCOS LLORACH, Emilio. Gramática de la lengua española. Madrid: Espasa, 2005.

ARAUJO, Leandro Silveira. Os valores atribuídos ao pretérito perfecto compuesto nas regiões dialetais argentinas. 2012. 212 fl. Dissertação (Mestrado em Linguística e Língua Portuguesa) - Faculdade de Ciências e Letras da Universidade Estadual Paulista 'Júlio de Mesquita Filho', Araraquara, 2012a.

ARAUJO, Leandro Silveira. A elaboração de um corpus dialetal da língua espanhola falada na Argentina: contribuições dos gêneros discursivos e da análise textual automática. Estudos Linguísticos, n. 41, v. 1, p. 246-261, 2012 b.

ARAUJO, Leandro Silveira. O pretérito em espanhol: usos e valores do perfecto compuesto nas regiões dialetais argentinas. São Paulo: Cultura Acadêmica, 2013.

ARAUJO, Leandro Silveira. O estudo da temporalidade verbal na língua espanhola: contribuições à dialetologia argentinca. In: COSTA, Daniel Soares da. (Org.). Pesquisas linguísticas pautadas em corpora. São Paulo: Editora Unesp Digital, 2015. p. 111-152.

BELLO, Andrés; CUERVO Rufino José. Gramática de la lengua castellana. 4. ed. Buenos Aires: ESA, 1954.

BENVENISTE, Émile. Problemas de linguísticageral. 2. ed. Campinas: Pontes, 2006. 2 v. BERLINCK, Rosane de Andrade. The Portuguese dative. In: W Van Belle; W Van Langendonck (Org.). The dative. descriptive Studies. Amsterdam: John Benjamins, 1996. v. 1 , p. $119-151$ 
CAMACHO, Roberto Gomes. Uma reflexão crítica sobre a teoria sociolinguística. DELTA, São Paulo, v. 26, n. 1, 2010.

CAMPOS, Héctor. Transitividad e intransitividad. In: BOSQUE, Ignacio; DEMONTE, Violeta. Gramática descriptiva de la lengua española. Madrid: Espasa, 1999. $2 \mathrm{v}$. p. 1521-1574.

CARTAGENA, Nelson. Los tiempos compuestos. In: BOSQUE, I.; DEMONTE, V. Gramática descriptiva de la lengua española. Madrid: Espasa, 1999. 2 v. p. 2933-2975.

CHAMBERS, Jack K. Sociolinguistic theory: linguistic variation and its social significance. Oxford: Blackwell Publishers, 2003.

COMPANY COMPANY, Concepción. Gramaticalización y dialectología comparada. Una Isoglosa sintáctico-semántica del español. Dicenda: Cuadernos de filología hispánica. Madrid, v. 20, p. 39-71, 2002.

COMRIE, Bernard. Aspect. Cambridge: Cambridge University Press, 1976.

COSERIU, Eugenio. El español de américa y la unidad del idioma. In: SIMPOSIO DE FILOLOGÍA IBEROAMERICANA, 1, 1990, Sevilla. Separata del I Simposio de filología iberoamericana. Sevilla: Universidad de Sevilla, 1990. p. 43-75.

GARCÍA FERNÁNDEZ, Luis. El aspecto gramatical en la conjugación. 2. ed. Madrid: Arco Libros, 2008.

GILI GAYA, Samuel. Curso superior de sintaxis española. 9. ed. Barcelona: Biblograf, 1970.

GUTIÉRREZ ARAUS, María Luz. Caracterización de las funciones del pretérito perfecto en el español de América. In: CONGRESO INTERNACIONAL DE LA LENGUA ESPAÑOLA, 2. 2001, Valladolid. Paneles y ponencias del II Congreso Internacional de la Lengua Española. Madrid: Centro Virtual Cervantes, 2001.

HOWE, Chad; SCHWENTER, Scott A. Present Perfect for Preterite across Spanish Dialects. Penn working papers in linguistics. Pennsylvania, v. 9, n. 2, p. 61-75, 2003.

HURTADO GONZÁLEZ, Silvia. El perfecto simple y el perfecto compuesto en el español actual: estado de la cuestión. EPOS, n. 15, p. 51-67, 1998.

JARA YUPANQUI, Ileana Margarita. El pretérito perfecto simple y el pretérito perfecto compuesto en las variedades del español peninsular y americano. Signo e Seña, Buenos Aires, n. 20, p. 255-281, 2009.

KANY, Charles Emil. Sintaxis hispanoamericana. Madrid: Gredos, 1969.
KUBARTH, Hugo. El uso del pretérito simple y compuesto en el español hablado en Buenos Aires. Scripta Philologica in Honorem Juan M. Lope Blanch, Ciudad de México, v. 2, p. 553-566, 1992.

LABOV, Willian. Where does the linguistic variable stop? A response to Beatriz Lavandera. Working Papers in Sociolinguistics, number 44. Austin:Southwest Educational Development Laboratory, 1978.

LABOV, Willian.; WEINER, Judith. Constraints on the agentless passive. Journal of Linguistic. Cambridge, v. 19, p. 29-58, 1983.

LABOV, Willian. Padrões Sociolinguísticos. Trad. Marcos Bagno. São Paulo: Parábola, 2008.

LAVANDERA, Beatriz R. Where does the sociolinguistic variable stop? Language in Society, Cambridge, v. 7, p. 171-182, 1978.

LAVANDERA, Beatriz R. Variación y significado. Buenos Aires: Hachette, 1984.

MARTÍNEZ GARCÍA, Hortensia. Construcciones temporales. Madrid: Arco Libros, 2003.

MONTEIRO, José Lemos. Para compreender Labov. Petrópolis: Vozes, 2002.

MORENO DE ALBA, José Guadalupe. El español en América. Ciudad de México: FCE, 2000.

OLIVEIRA, Leandra Cristina. As duas formas do pretérito perfeito em espanhol: análise de corpus. 2007. 130 fl. Dissertação (Mestrado em Linguística) - Universidade Federal de Santa Catarina, Florianópolis, 2007.

RAE. Esbozo de una nueva gramática de la lengua española. Madrid: Espasa, 1986.

RAE. Nueva gramática de la lengua española. Madrid: Espasa, 2009.

ROJO, Guillermo. La temporalidad verbal en español. Verba: Anuário Gallego de Filología, Santiago de Compostela, v. 1, p. 69-149, 1974.

ROJO, Guillermo. Relaciones entre temporalidad y aspecto en el verbo español. In: BOSQUE, Ignacio (Org.). Tiempo y aspecto en español. Madrid: Cátedra, 1990 p. 17-43.

ROJO, Guillermo.; VEIGA, Alexandre. El tiempo verbal: los tiempos simples. In: BOSQUE, Ignacio; DEMONTE, Violeta. Gramática descriptiva de la lengua española. Madrid: Espasa, 1999. 2 v. p. $2867-2934$.

SANKOFF, David. Sociolinguistic method and linguistic theory. In: COHEN, J. J. et al. (Ed.). Logic, Methodolody and Philosophy of Science. Amsterdam: North-Holland, p. 677-689, 1982 
SANKOFF, David. Sociolinguistic and syntactic variation. In: NEWMEYER, Frederick. Linguistics: The Cambridge survey. Cambridge: Cambridge University, 1988.

SERRANO, María José. Cronología del estudio de la variación sintáctica en español: pasado y presente. Revista de Filología, La Laguna, n. 27, p. 155-170, 2009.

SILVA-CORVALÁN, Carmen. Sociolinguística: teoria y análisis. Madrid: Alhambra, 1989.

SOSA, Mercedes. Mi unicornio azul. Silvio Rodríguez [Compositor]. In: SOSA, Mercedes. Mercedes Sosa: 30 años. [S.I.]: Universal, 2004.

WEINREICH, Uriel.; LABOV, Willian.; HERZOG, Marvin. Fundamentos empíricos para uma mudança linguística. Trad. Marcos Bagno. São Paulo: Parábola, 2006.

Recebido em 26/08/2016.

Aceito em 13/02/2017. 